\title{
KONVERGENSI DAN PERUBAHAN SOSIAL: INTERAKSI PENONTON ASIAN GAMES 2018 PADA KANAL EMTEK
}

\author{
Teguh Setiawan Imam Santoso ${ }^{1}$ Denik Iswardani Witarti² \\ ${ }^{1}$ Akademi Televisi Indonesia (ATVI) \\ Jl. Damai No. 11, Daan Mogot, Jakarta Barat, Daerah Khusus Ibukota Jakarta, 11510, Indonesia \\ ${ }^{2}$ Magister Ilmu Komunikasi, Fakultas Ilmu Komunikasi, Universitas Budi Luhur \\ Jl Ciledug Raya, Petukangan Utara, Jakarta Selatan, Daerah Khusus Ibukota Jakarta, 12260, Indonesia \\ No. Telp./HP: ${ }^{1}(021) 56976833,{ }^{2}(021) 5853753$ \\ E-mail: ${ }^{1}$ teguh.setiawan@atvi.ac.id, ${ }^{2}$ denik.iswardani@budiluhur.ac.id
}

Naskah diterima tanggal 6 Desember 2019, direvisi tanggal 29 Juni 2020, disetujui tanggal 19 Agustus 2020.

\section{CONVERGENCE AND SOCIAL CHANGE: THE INTERACTION OF ASIAN GAMES'S 2018 VIEWERS ON EMTEK CHANNELS}

\begin{abstract}
In the new media era, Elang Mahkota Teknologi Group (Emtek Group) has converged following the era's demands. When they obtained broadcast rights for Asian Games (AG) 2018, this group undertook media convergence to broadcast the games. This article aims to analyze the utilization of digital channels to attract viewers during the Asian Games. This study used a qualitative approach with descriptive analysis using both primary and secondary data. The result showed that Emtek Group established a special channel for the 2018 Asian Games, namely KapanLagi Youniverse Sport, besides the existing channels. Emtek Group also distributed content through conventional televisions (free-to-air) and a delayed broadcast (video on demand) on their digital channels. All Emtek Group s channels potentially attracts viewers to watch the match of the Asian Games.
\end{abstract}

Keywords: Emtek Grup, digital channels, convergence, new media, social change.

\begin{abstract}
Abstrak. Di era media baru, Elang Mahkota Teknologi Grup (Emtek Grup) telah melakukan konvergensi sesuai dengan tuntutan zaman. Ketika mendapatkan hak siar Asian Games 2018, Emtek Grup melakukan konvergensi media secara khusus untuk menayangkan pertandingan. Tulisan ini bertujuan menganalisis pemanfaatan kanal-kanal digital Emtek Grup untuk menarik penonton pertandingan olahraga selama Asian Games berlangsung. Penelitian ini menggunakan pendekatan kualitatif dengan analisis deskripstif terhadap data primer dan sekunder. Hasil penelitian menunjukkan bahwa Emtek Grup telah membuat kanal khusus untuk Asian Games 2018 yaitu KapanLagi Youniverse Sport, selain kanal-kanal digital yang sudah ada. Emtek Grup juga melakukan distribusi konten melalui televisi konvensional (free-to-air) dan siaran tunda (video on demand) di kanal digitalnya. Semua kanal Emtek Grup memiliki kekuatan untuk menarik penonton menyaksikan pertandingan Asian Games.
\end{abstract}

Kata kunci: Emtek Grup, kanal digital, konvergensi, media baru, perubahan sosial.

\section{PENDAHULUAN}

Kemajuan di bidang teknologi, informasi dan komunikasi (TIK), terutama internet, membawa dampak yang besar terhadap perkembangan media. Masyarakat kini mendapatkan sebuah layanan data dan akses komunikasi dengan kecepatan tinggi. Teks, audio, dan visual dapat diakses secara bersamaan dan simultan dengan adanya internet. Hal tersebut secara langsung berpengaruh terhadap perubahan aktivitas di 
industri komunikasi. Perubahan itu menyebabkan tersedianya berbagai sumber yang mudah diakses oleh masyarakat, seperti disampaikan oleh McNamus dalam (Nasrullah, 2014) bahwa terjadi pergeseran berkenaan dengan ketersediaan media. Akses ke media yang dahulu langka dan terbatas kini berlimpah.

Hampir semua pelaku industri media kini melakukan konvergensi yaitu pengintegrasian media-media yang ada, digabung dan digunakan untuk mengarah ke satu titik tujuan (Briggs \& Burke, 2000). Hal ini akhirnya melahirkan fenomena baru. Teknologi komputer yang maju pesat, internet yang semakin interaktif dipadu dengan komunikasi konvensional membuat pola komunikasi masyarakat juga berubah. Fenomena inilah yang disebut sebagai proses konvergensi. Dalam konteks seperti ini konvergensi media dipahami sebagai perpaduan media yang beragam dari teknologi komunikasi yang tradisonal dengan teknologi komunikasi baru (Preston, 2001).

Industri media kini dituntut untuk memenuhi kebutuhan masyarakat dalam memperoleh informasi dan hiburan secara mudah dan cepat seiring dengan kemajuan teknologi. Perkembangan teknologi internet yang begitu pesat memungkinkan masyarakat menonton tayangan yang diinginkan melalui perangkat gawai. Media penyiaran dipaksa untuk merespon perubahan teknologi tersebut jika tidak ingin ditinggalkan pemirsanya. Konvergensi media kemudian dilakukan oleh sejumlah media dengan memanfaatkan teknologi internet. Menurut Julijanti (2012) kunci konvergensi adalah digitalisasi, karena semua bentuk informasi dan data dalam bentuk digital. Konvergensi menuntut semua produk diciptakan dalam bentuk digital, yang memiliki fungsi audio visual sekaligus komputasi. Hasil produksi yang ditayangkan dalam bentuk digital memudahkan orang untuk menonton dari mana saja. Hal ini akhirnya menimbulkan pola komunikasi baru di antara penonton.

Elang Mahkota Teknologi Grup (Emtek Grup) sebagai sebuah perusahaan besar di bidang media tidak luput melakukan konvergensi. Pada tahun 2002 Emtek Grup memulai konvergensi saat mengambil alih kepemilikan Surya Citra Televisi (SCTV), kemudian dilanjutkan tahun 2011 dengan mengakuisisi Indosiar. Konvergensi di bidang teknologi diawali dengan mendirikan anak usaha PT. Kreatif Media Karya (KMK Online) pada tahun 2012. KMK Online merupakan usaha Emtek Grup yang ikut serta dalam pengembangan industri digital dan usaha terkait lainnya di Indonesia. Portal-portal internet yang beroperasi di bawah KMK Online seperti portal berita Liputan6.com, portal berbasis video Vidio.com, portal hiburan Bintang.com, portal olahraga Bola.com, dan portal kerja Karier.com yang diciptakan untuk mendukung pertumbuhan Emtek Group di industri online.

Terobosan terbesar dalam melakukan konvergensi adalah saat Emtek Grup menjalin kerja sama dengan Blackberry. Keduanya menyepakati kerja sama berkaitan dengan brand perjanjian lisensi software, dan hak kekayaan intelektual atas aplikasi pesan instan BlackBerry Messenger (BBM). Konten-konten yang dihasilkan Emtek Grup seperti video, acara televisi free-to-air atau koleksi konten TV dengan lebih dari 100 ribu jam tayang, semuanya dapat diakses oleh para pengguna aplikasi pesan instan BBM (Nistanto, 2016).

Emtek Grup juga melakukan konvergensi dengan mengakuisisi PT. Kapan Lagi Network (KLN) sebuah perusahaan portal berita yang cukup terkenal. Melalui anak usahanya, KMK Online berhasil menguasai $50 \%$ plus satu saham di Kapanlagi (Yuliawati, 2018). KLN kemudian diganti nama menjadi Kapanlagi Youniverse (KLY). Portal digital yang dikelola semakin banyak yaitu Vidio.com, Liputan6.com, Kapanlagi.com, Bola.net, Merdeka.com, Bola.com, Dream.co.id dan Fimela.com. Portal-portal yang menyediakan konten berita, gaya hidup, hiburan, dan olahraga tersebut memiliki jumlah pengguna millennial terbesar. KMK telah mengukuhkan keberadaannya sebagai grup media digital yang memiliki media vertikal terlengkap dan terdepan baik teknologi maupun konten multimedianya. 


\section{KLY became The Largest Digital Media Group in Indonesia by merging KMK Online with Kapan Lagi Network (KLN)}
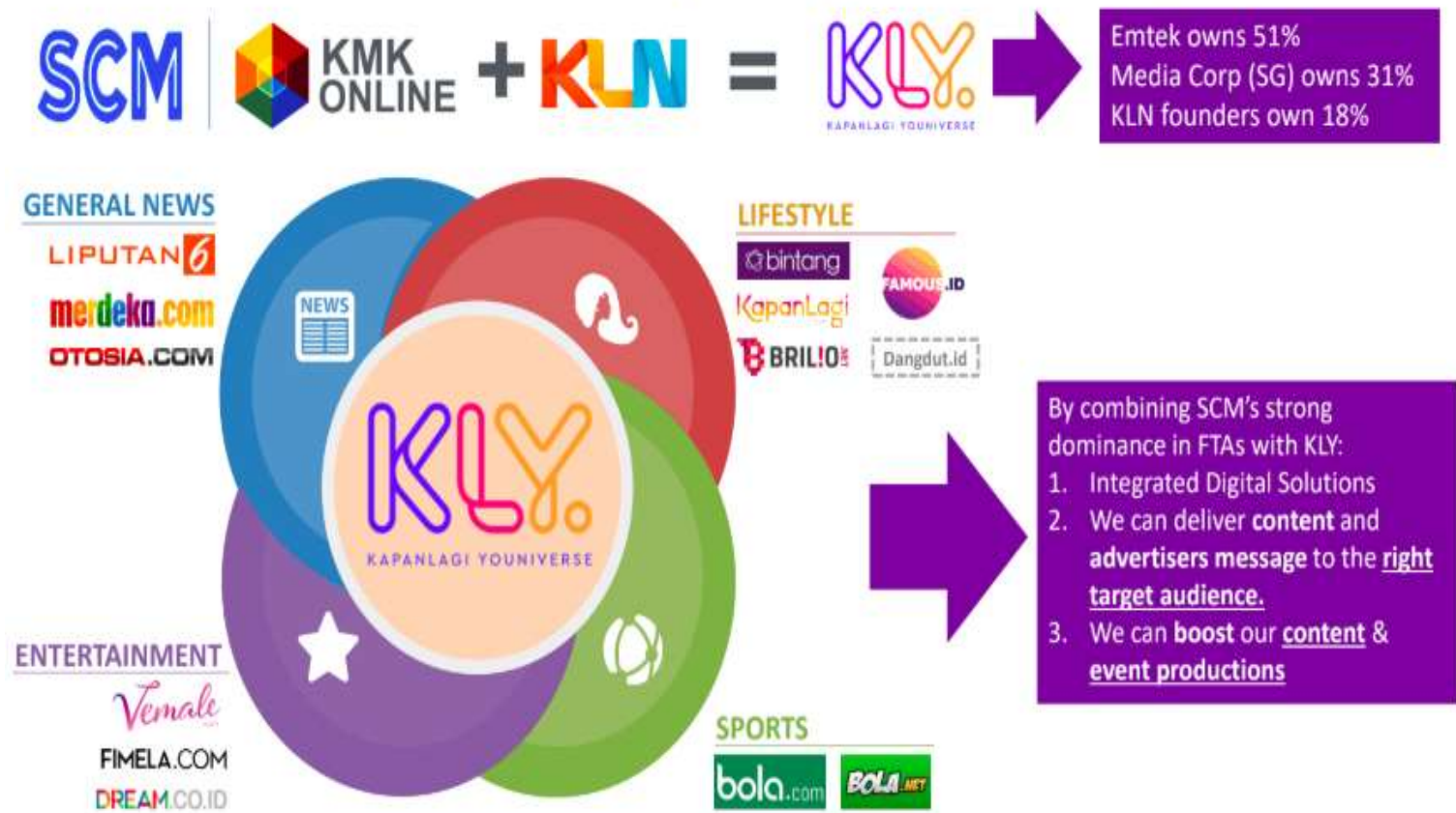

Sumber: www.emtek.co.id

Gambar 1. Merger KMK Online dan KLN.

Tahun 2018 Emtek Grup ditunjuk sebagai official broadcaster Asian Games 2018. Hak siar Asian Games 2018 dipegang oleh perusahaan penyiaran asal Jepang bernama Dentsu. Sedangkan Emtek Grup memegang hak siar untuk Indonesia. Dengan demikian Emtek Grup memiliki hak siar untuk menayangkan pertandingan Asian Games melalui televisi terestrial (SCTV, Indosiar, O Channel), satelit (Nexmedia), kanal digital (Vidio.com) serta aplikasi BBM. Namun dengan alasan nasionalisme, Emtek Grup bersedia membagi hak siar tersebut kepada sejumlah televisi nasional kecuali siaran pertandingan sepak bola dan bulu tangkis.

Proses mendapatkan hak siar didahului dengan dibukanya tender oleh pemegang hak siar Asian Games 2018 yaitu Dewan Olimpiade Asia (OCA) dan Dentsu dari Jepang. Dentsu kemudian menjual hak siar itu ke berbagai negara, termasuk Indonesia. Tender tersebut bersifat terbuka sehingga siapapun dapat ikut sejauh memenuhi syarat yang telah ditetapkan. Emtek Grup berinisiatif mengikuti tender tersebut. Dengan integrasi platform media terbaik yang dimiliki, akhirnya
Emtek Grup terpilih sebagai pemegang hak siar Asian Games 2018 (Gilang Iskandar, wawancara pada 2 Mei 2019).

Seiring dengan perubahan cara menonton masyarakat akibat kemajuan teknologi, Emtek Grup dituntut menyajikan tayangan terbaik bagi pemirsanya. Sejumlah persiapan melalui KLY telah dilakukan mengikuti standar yang telah ditentukan Komite Olimpiade Internasional (IOC). Sebagai pemilik hak siar Asian Games 2018, Emtek Grup telah melakukan persiapan dengan menyediakan konten-konten terkini dan interaktif yang dapat dinikmati para penonton Asian Games. Emtek Grup menyiarkan Asian Games 2018 melalui 16 kanal dengan tiga di antaranya melalui free-toair yakni Indosiar, SCTV dan O Channel, sisanya melalui digital.

Konvergensi media sangat berkaitan erat dengan perubahan industri yang lebih dinamis dan bergantung pada teknologi. Dalam penelitian ini, konvergensi media tidak hanya dipahami sebagai pergeseran teknologi atau proses teknologi saja. Konvergensi media juga diperhatikan sebagai pergeseran dalam 
paradigma industri, budaya, dan sosial yang mendorong konsumen untuk mencari informasi baru. Konvergensi telah mengubah hubungan antara teknologi, industri, gaya hidup, dan masyarakat. Dengan adanya konvergensi melahirkan interaktivitas antara industri dan khalayaknya.

Di era konvergensi, teknologi informasi berkembang tidak terbendung seiring dengan kemajuan internet dan inovasi-inovasi gawai yang semakin canggih. Era konvergensi ini juga mengubah penonton dalam menikmati tayangan. Saat ini penonton tidak hanya sebagai penikmat tetapi dapat berpartisipasi aktif dalam sebuah tayangan. Penonton secara interaktif juga dapat memberikan masukan, kritik, bahkan berkomunikasi dengan khalayak lainnya. Hubungan yang terjalin antara televisi dengan internet dan media sosial dapat meningkatkan ikatan antara program acara televisi dengan khalayak atau penontonnya (Nielsen, 2013).

Banyaknya kanal yang digunakan untuk menayangkan Asian Games 2018 tersebut memudahkan para penonton untuk saling terhubung. Tingginya aktivitas penonton selama Asian Games 2018 juga menunjukkan adanya peningkatan interaksi. Berbagai tagar tentang Asia Games bermunculan di media sosial, misalnya tagar \#indonesiabangga, \#openingceremonyAsianGames2018, dan tagar \#Asiangames2018, serta berbagai tagar lainnya. Interaksi penonton terjadi dengan saling berkomentar dalam berbagai tagar tersebut.

Fokus penelitian ini adalah menganalisis bagaimana konvergensi yang dilakukan oleh Emtek Grup dapat memengaruhi perilaku penonton pertandingan Asian Games 2018. Untuk menjawab permasalahan tersebut, dalam studi ini akan dijelaskan kanal-kanal apa saja yang disediakan oleh Emtek Grup untuk menayangkan pertandingan selama Asian Games 2018. Tujuan lainnya adalah untuk menganalisis interaksi sosial yang terjadi di antara penonton dan pendukung Indonesia selama mereka menyaksikan pertandingan Asian Games 2018 di kanal digital Emtek Group. Secara teoretis, penelitian ini memberi sumbangan keilmuan sebagai dasar empiris dalam mengkaji konvergensi media. Sedangkan secara praktis, hasil temuan penelitian dapat dimanfaatkan para pemangku kepentingan media dalam mengembangkan konten dan meningkatkan interaksi penonton di kanal-kanal digitalnya.

\section{LANDASAN KONSEP}

Kemajuan teknologi telah membawa pengaruh besar di dalam masyarakat sekarang. Sehubungan dengan hal itu, McLuhan pada tahun 1962 memunculkan teori determinasi teknologi yang menjelaskan bagaimana perubahan terjadi pada segala cara berkomunikasi manusia yang pada akhirnya akan membentuk keberadaan manusia itu sendiri. Tidak ada manusia yang dapat menghindar untuk bersentuhan dengan teknologi. Perspektif teori yang disampaikan oleh McLuhan ini menganggap bahwa media itu sendiri lebih penting dari isi pesan, atau medium is the message (McLuhan, 2003). Pemikiran McLuhan juga diperkuat oleh E.M. Griffin yang menyebutkan nothing remains untouched by communication technology. Dengan kemajuan teknologi yang semakin berkembang, manusia dimudahkan dalam segala aspek kehidupannya sehingga berdampak juga pada perubahan kebudayaan yang semakin maju dan manusia sekarang berkehendak ingin serba cepat dan instan (Griffin, 2011).

Teori determinasi teknologi McLuhan secara empiris dapat dimanfaatkan oleh industri media untuk menjalin komunikasi yang lebih dekat, membangun cara berpikir dan membentuk perilaku masyarakat. Industri media kemudian memasuki era media baru (new media). Media melakukan konvergensi dengan membuka kanal-kanal digital. Setiap kanal memiliki media sosial sehingga berita atau informasi yang terkini mengenai program-programnya lebih mudah dan cepat diketahui khalayak (penonton). Ini menjadi salah satu kemudahan yang ditawarkan oleh media sosial, yaitu memberi kesempatan setiap manusia untuk bersentuhan satu sama lainnya, kapan saja, di mana saja dan seketika itu juga (Baran, 2010). Konvergensi telah memengaruhi cara menonton dan juga membuka kemungkinan bagi para penonton untuk saling berinteraksi. 
Berdasarkan pemaparan di atas, penelitian ini dikembangkan dengan menggunakan kerangka analisis teori konvergensi media yang dikenalkan oleh Henry Jenkins. Menurut Jenkins, proses terjadinya konvergensi media berjalan seiring dengan perkembangan budaya masyarakat. Jadi bukan hanya sekedar proses pergeseran teknologi, namun konvergensi media juga bersentuhan dengan perubahan paradigma industri, budaya, dan sosial yang mendorong khalayak untuk mencari informasi baru. Jenkins juga melihat bagaimana interaksi antarindividu pada tingkat sosial dengan menggunakan berbagai platform media dapat menciptakan pengalaman baru, bentuk-bentuk baru media dan konten. Pada akhirnya interaksi tersebut secara sosial menghubungkan tidak saja di antara konsumen, melainkan juga antara para produsen perusahaan media (Jenkins, 2006). Masyarakat berkembang menjadi jaringan sosial penonton yang aktif dan bahkan interaktif. Ketersediaan media-media baru tersebut telah memudahkan atau memberikan fasilitas kepada para penonton televisi untuk saling terhubung, bahkan hingga tingkat global (Jenkins, 2006; Goggin, 2006; Shirky, 2010).

\section{METODE PENELITIAN}

Penelitian ini dilakukan dengan menggunakan pendekatan kualitatif dan teknik analisis deskriptif terhadap data yang didapat secara primer dan sekunder. Data primer didapat dengan melakukan wawancara kepada beberapa informan. Penentuan informan menggunakan teknik purposive sampling berdasarkan kriteria atau pertimbangan tertentu yaitu kapasitas dan kapabilitasnya. Para informan dalam penelitian ini merupakan orang-orang yang menguasai permasalahan, memiliki data yang memadai dan bersedia memberikan informasi yang lengkap dan akurat. Berikut ini adalah nama-nama informan lengkap dengan jabatan yang diampu ketika wawancara dilaksakanan; Gilang Iskandar (Corporate Secretary PT. Surya Citra Media/SCM), Karaniya Dharmasaputra (Deputy CEO Kapanlagi Universe), Darojatun (Vice President of Sports Content, Kapanlagi
Youniverse) dan Agus Sudibyo (Direktur Indonesia New Media Watch).

Sedangkan data sekunder dilakukan dengan studi kepustakaan. Selain melakukan kajian literatur terhadap jurnal-jurnal yang relevan, data sekunder juga diperoleh dari dokumentasi dari Divisi Programing SCM, Kapanlagi Youniverse social media team, serta data terbuka dari Nielsen Television Audience Measurement (TAM).

\section{HASIL PENELITIAN DAN PEMBAHASAN}

Pertumbuhan media yang pesat ditunjang dengan perkembangan teknologi membuat Emtek Grup menjadi salah satu raksasa media di Indonesia. Emtek Grup terus melakukan pengembangan bisnisnya di bidang media. Integrasi tersebut di antaranya melalui berbagai upaya pengambilalihan kepemilikan (akuisisi), penggabungan perusahaan, membentuk unit bisnis baru baik yang masih berkaitan dengan media maupun di luar bisnis utama mereka (Ma'arief Alyatalatthaf, 2018). Namun sejak mengambil alih kepemilikan SCTV, fokus bisnis Emtek Grup berubah dari bisnis peralatan komputer menjadi bisnis media. Divisi media merupakan portofolio bisnis utama Emtek Grup. Divisi ini mengelola tiga usaha bisnis yaitu bidang konten, bidang online, dan bidang penyiaran.

Keberhasilan menjadi pemegang hak siar Asian Games 2018 menunjukkan kepercayaan terhadap Emtek Grup, meskipun bukan pemain baru di industri media. Perusahaan ini sudah berpengalaman menyelenggarakan kejuaraan multi even tingkat internasional. Mereka telah menjadi pemegang hak siar SEA Games 2011, SEA Games 2017 di Malaysia, Shopee Liga 1 tahun 2019 dan beberapa even olahraga lainnya.

Pada awalnya memang banyak kalangan media lain menilai bahwa Emtek Grup memiliki hak siar yang cukup mewah untuk Asian Games. Namun ada kekhawatiran dari berbagai pihak bahwa Emtek tidak punya cukup slot untuk memberitakannya. Untuk menjawab kekhawatiran tersebut, Darojatun selaku Vice President of Sports Content, Kapanlagi Youniverse menyatakan bahwa 
Emtek telah melakukan berbagai upaya perbaikan sejak tahun 2012. Salah satunya dengan memanfaatkan kanal Vidio.com dan juga seluruh kanal media yang ada di KLY. Keterbatasan slot di free-to-air dapat diatasi dengan tersedianya tayangan di kanal Vidio.com, Bola.com, Bola.net, Liputan6.com, Merdeka.com, Kapanlagi.com, Brilio.net. Selain itu, pertandingan Asian Games 2018 juga dapat disaksikan melalui video on demand (VoD) (Darojatun, wawancara pada 2 April 2019). Ini menunjukkan Emtek Grup telah berupaya memanfaatkan hak siarnya secara optimal melalui semua kanal digitalnya

Asian Games adalah perhelatan olahraga terbesar di Asia. Menurut Indonesian Asian Games Organizing Committee (INASGOC), Asian Games yang berlangsung pada 18 Agustus hingga 2 September 2018 di Jakarta dan Palembang disiarkan secara langsung oleh 20 negara. Sebagai sebuah peristiwa olah raga terbesar kedua setelah olimpiade, tidak mengherankan jika Asian Games banyak diminati oleh lembaga-lembaga penyiaran di masing-masing negara untuk menjadi pemilik hak siarnya. Emtek Grup melakukan segala persiapan sesuai standar International Olympic Committee (IOC) setelah terpilih sebagai pemilik hak siar Asian Games 2018. Gilang Iskandar, Corporate Secretary Surya Citra Media menjelaskan bahwa semua yang dilakukan dalam hal penyiaran seperti teknologi, jenis peralatan dan kamera yang digunakan secara operasional mengikuti acuan dari IOC (Gilang Iskandar, wawancara pada 2 Mei 2019).

Kesiapan teknologi menjadi hal yang dipertimbangkan dalam penyelenggaraan Asian Games 2018. Emtek Grup dituntut tidak hanya mengandalkan siaran melalui satu platform saja. Karaniya Dharmasaputra, Deputy CEO Kapanlagi Youniverse dalam wawancara menyatakan bahwa kepercayaan tersebut karena Emtek Grup memiliki visi sangat konvergen. Selain itu, Emtek Grup merupakan perusahaan yang memiliki tidak hanya televisi terestrial tetapi juga digital. Emtek Grup memiliki platform digital yang sangat kuat (Karaniya Dharmasaputra, wawancara $\operatorname{tgl} 8$ April 2019). Untuk menyiarkan pertandingan Asian Games 2018,
Emtek Grup mengandalkan televisi free-to-air (FTA) seperti SCTV, Indosiar dan O Channel. Selain itu, seluruh konten seputar Asian Games juga tersedia melalui kanal digitalnya. Banyaknya platform yang digunakan ini merupakan implementasi dari konvergensi yang dilakukan Emtek Grup yang berpengaruh terhadap cara menonton. Sinergi antara FTA dan streaming siaran memudahkan penonton dalam menikmati tayangan.

\section{Kanal Free-to-Air (FTA)}

Free-to-air merupakan siaran yang berasal dari stasiun televisi teresterial yang salurannya dapat ditonton tanpa harus berlangganan seperti siaran TV berbayar (Setyobudi \& Sjailendra, 2017). Siapapun dapat menangkap siaran ini secara gratis dengan menggunakan antena UHF/VHF, atau menggunakan antena parabola. Siaran pertandingan Asian Games 2018 melalui televisi FTA masih dapat diandalkan untuk menjangkau penonton. Emtek Grup mengoptimalkan jaringan televisi di dalam grupnya seperti SCTV, Indosiar dan O Channel. Pertandingan Asian Games disiarkan selama hampir 24 jam di semua televisi Emtek Grup. SCTV menyiarkan dari pukul 12.00 WIB hingga pukul 17.00 WIB, dilanjutkan oleh Indosiar pada pukul 17.00 hingga pukul $22.00 \mathrm{WIB}$, dan siaran malam hari tayang di O Channel dan kanal televisi berbayar Nexmedia.

Sebagai pemilik hak siar Emtek juga harus mengikuti aturan yang diberikan oleh Dewan Olimpiade Asia (OCA). Siaran itu hanya dapat dilakukan melalui tiga saluran, yaitu: terestrial, layanan televisi kabel dan siaran digital melalui jaringan internet. Sesuai dengan ketentuan yang ada, siaran Asian Games 2018 tidak dapat diakses melalui satelit Palapa (encrypted), kecuali siaran langsung Opening dan Closing Ceremony Asian Games 2018 (Liputan6.com, 2018). Hal ini untuk memenuhi ketentuan aturan hak siar yang telah ditetapkan oleh OCA dan menghindari penerimaan siaran di luar wilayah Indonesia.

Namun, Emtek berkomitmen untuk menjaga nasionalisme demi kepentingan nasional, sehingga pertandingan Asian Games 2018 juga disiarkan melalui lembaga siar di luar grupnya. Strategi agar seluruh masyarakat 
Indonesia dapat menyaksikan tayangan Asian Games 2018 adalah Emtek juga bekerjasama dengan beberapa stasiun TV lain yang tergabung sebagai Emtek Broadcast Partner. Emtek membagi hak siarnya dengan TVRI, TVONE dan Metro TV untuk menayangkan beberapa cabang olahraga dari venue tertentu. Emtek Grup bersinergi dengan Emtek Broadcast Partner antara lain Metro TV, TV One, TVRI. Selain sinergi dengan beberapa televisi lain, pertandingan Asian Games juga dapat disaksikan melalui Emtek Radio Partner yaitu seluruh televisi berbayar dan RRI untuk meningkatkan dukungan warga Indonesia, Menurut Gilang Iskandar kerjasama dengan televisi di luar grup dilatarbelakangi terutama berdasarkan kepentingan nasional agar semua masyarakat Indonesia dapat menikmati Asian Games.

Hasil pantauan Nielsen Television Audience Measurement (TAM) di 11 kota menunjukkan peningkatan tren jangkauan tayangan sepanjang pelaksanaan Asian Games 2018 dari tanggal 18 Agustus - 2 September 2018. Jangkauan penonton televisi Asian Games 2018 ini berhasil mencapai 85,4\%. Acara pembukaan Asian Games 2018 di 11 stasiun TV mampu mencapai angka yang cukup tinggi yakni $14 \%$, dengan share mencapai $57,2 \%$. Sedangkan penutupannya mencapai angka $14,5 \%$, dengan share mencapai 55,7\% (Nielsen, 2018). Hal menarik berkaitan dengan gender penonton. Program olahraga yang biasanya didominasi oleh penonton pria, sepanjang Asian Games 2018 didominasi oleh penonton wanita.

Data dari bagian Programming SCM (Tabel 1) menunjukkan kenaikan audience share performance tayangan Asian Games jika dibandingkan dengan acara reguler. Stasiun televisi Indosiar dan SCTV menduduki peringkat teratas dari 11 stasiun TV yang menayangkan siaran pertandingan Asian Games.

Dari Tabel 1, persentase kenaikan TV One, Metro TV, dan TVRI memang lebih tinggi dibandingkan Indosiar dan SCTV. Hal itu terjadi karena jumlah penayangan siaran pertandingan Asian Games di Indosiar dan SCTV lebih sedikit, meskipun keduanya memegang hak siar. Indosiar secara eksklusif hanya menayangkan pertandingan bulutangkis, sedangkan SCTV menyiarkan sepakbola. TV One dan Metro TV memiliki jam tayang yang cukup banyak, baik melalui tayangan langsung maupun kemasan berita. TVRI persentasenya paling besar karena sebagai televisi nasional memiliki jangkauan yang paling luas dan jam siarannya yang tidak terganggu oleh adanya iklan.

\section{Kanal Digital}

Selain menyiarkan melalui FTA, Emtek Grup juga menyediakan siaran pertandingan Asian Games melalui kanal-kanal digitalnya. Konvergensi ini dilakukan untuk memenuhi tuntutan kemajuan jaman yang membawa perubahan terhadap cara menonton masyarakat. Darojatun, Vice President of Sports Content pada KapanLagi Youniverse (KLY) menyatakan bahwa Emtek Grup telah melakukan persiapan dengan memperbaiki digital medianya, sejak setahun sebelum pelaksanaan Asian Games berlangsung. Persiapan dilakukan antara lain dengan membangun studio, membuat perencanaan distribusi konten termasuk mencari treatment antara video on demand ( $\mathrm{VoD}$ ) dengan media sosial, dengan live streaming (Darojatun, wawancara pada 2 April 2019).

Sepanjang Asian Games 2018, Kapan Lagi Youniverse (KLY) sebagai anak usaha Emtek Grup di bidang penyiaran digital telah menjadi ujung tombak dalam menyiarkan pertandingan yang berlangsung. KLY menaungi beberapa media daring yaitu Liputan6.com, Kapanlagi.com, Brilio.net, Merdeka.com, Dream.co.id, Bola.net, Bola.com, Otosia.com, Fimela.com, dan Famous.id. Selain KLY, Emtek Grup juga memanfaatkan Vidio.com yang merupakan media digital berbasis video. Karaniya Dharmasaputra, Deputi Chief Operating Officer (COO) KLY dalam wawancara menyatakan bahwa Emtek Grup memiliki kelebihan karena memiliki video platform. Traffic terbesar video di Indonesia setelah YouTube adalah Vidio.com. Hingga saat ini, belum ada satu media grup lokal di Indonesia yang memiliki platform video seperti Emtek Grup (Karaniya Dharmasaputra, wawancara pada 8 April 2018).

Pertandingan yang ada di FTA baik itu Indosiar, SCTV, dan O Channel ditayangkan 
juga dalam bentuk live streaming di Vidio.com. Sepanjang perhelatan Asian Games 2018, Vidio.com menjadi hub (pusat) dalam penayangan seluruh pertandingan. Semua yang ada di Vidio.com kemudian didistribusikan lagi ke beberapa kanal. Total kanal yang digunakan dalam rangka Asian Games 2018 berjumlah total 13 yaitu 12 kanal di Vidio.com dan 1 kanal KLY sport. Semua kanal baik FTA baik di KLY maupun kanalkanal digital lainnya akan disiarkan juga di Vidio.com (Darojatun, wawancara pada 2 April 2019). Kanal KLY menyiarkan seluruh pertandingan dari Senin-Minggu mulai pukul 8 pagi hingga 10 malam. Kanal KLY Sport walaupun hanya satu namun dalam menyiarkan pertandingan Asian Games menggunakan lima vertikal di bawahnya. Pembagian program dalam setiap kanal tidak secara spesifik ditentukan untuk suatu cabang olahraga tertentu. Dalam menayangkan pertandingan ini Vidio.com memiliki strategi agar setiap tayangan memiliki banyak penonton. Tidak semua kanal digunakan untuk seluruh pertandingan. Beberapa cabang olahraga seperti sepakbola dan bulutangkis bisa menghasilkan live streaming tinggi yang diprioritaskan untuk ditayangkan (Darojatun, wawancara pada 2 April 2019).

Selain kanal-kanal digital tersebut, siaran pertandingan Asian Games juga dapat diakses melalui BBM. BBM menghadirkan fitur khusus tersebut bernama Discover (Budiawati, 2018). Fitur ini memungkinkan pengguna BBM menyaksikan pertandingan tanpa menonton televisi. Seluruh tayangan pertandingan Asian Games 2018 disaksikan secara live streaming langsung dari BBM.

Tabel 1

Audience Share Performance Siaran Pertandingan Asian Games 2018

\begin{tabular}{|c|c|c|c|c|}
\hline Kanal & Reguler & Asian Games & +1 & $+/-($ in $\%)$ \\
\hline Indosiar & 17.0 & 19.5 & 2.5 & $15 \%$ \\
\hline SCTV & 16.7 & 17.0 & 0.3 & $2 \%$ \\
\hline RCTI & 16.2 & 16.0 & -0.2 & $-1 \%$ \\
\hline ANTV & 13 & 12.4 & -1 & $-9 \%$ \\
\hline MNCTV & 8.2 & 7.6 & -0.6 & $-7 \%$ \\
\hline TRANS & 8.8 & 7.1 & -1.7 & $-19 \%$ \\
\hline TRANS 7 & 6.7 & 6.5 & -0.2 & $-3 \%$ \\
\hline GTV & 7.3 & 6.5 & -0.8 & $-11 \%$ \\
\hline TVONE & 2.9 & 3.6 & 0.7 & $24 \%$ \\
\hline METRO & 1.4 & 1.9 & 0.5 & $36 \%$ \\
\hline TVRI 1 & 1.0 & 1.7 & 0.7 & $70 \%$ \\
\hline
\end{tabular}




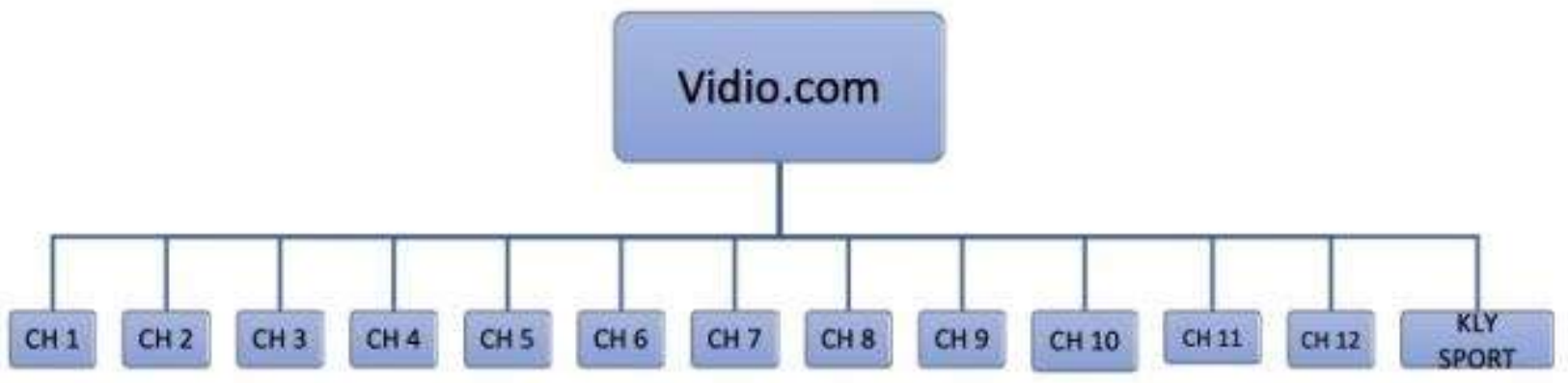

Gambar 2. Kanal Digital Asian Games 2018 di Vidio.com.

Fitur Discover BBM juga menyediakan perkembangan berita dan video seperti persiapan atlet, cuplikan pertandingan pilihan dan komentar setelah pertandingan sehingga para pengguna BBM tidak ketinggalan info terkini (Fauzan Jamaludin, 2018).

BBM menyediakan live TV yang dintegrasikan dengan video sehingga penonton bisa langsung menyaksikan lewat kanal ini, sedangkan kontennya dari KLY (Karaniya Dharmasaputra, wawancara pada tanggal 8 April 2019). Semua tayangan olahraga yang ada dapat dihadirkan melalui grup percakapan BBM yang anggotanya bisa mencapai 300 anggota. Grup di BBM memungkinkan para pengguna berbagi video dari platform video atau live TV dari Discover ke percakapan (pribadi atau grup) sehingga tayangan tersebut dapat ditonton dalam waktu bersamaan.

Cara menggunakan fitur tersebut, pengguna tinggal memilih menu Asian Games dari Discover atau dari attachment panel di dalam layar percakapan. Setelah itu, pilih video yang ingin disaksikan bersama teman, lalu pilih Send to Chat. Melalui fitur ini, para pengguna dapat mengekspresikan dan memberikan dukungan kepada atlet di dalam grup percakapan secara langsung sehingga acara menonton pertandingan menjadi lebih seru (Tempo.co, 2018).

Gilang Iskandar mengatakan bahwa sepanjang memenuhi yang dipersyaratkan oleh OCA, semua platform dapat digunakan. BBM merupakan salah satu platform digital yang punya pasar tersendiri dalam mendukung, berpartisipasi dan menyaksikan berbagai pertandingan olahraga Asian Games 2018 (Gilang Iskandar, wawancara pada 2 Mei 2019). Pemanfaatan kanal-kanal digital yang dimiliki oleh Emtek Grup dalam menyiarkan pertandingan Asian Games 2018 menunjukkan bagaimana konvergensi yang dilakukan telah memengaruhi cara menonton masyarakat. Fenomena ini sesuai dengan pandangan McLuhan dalam teori determinasi teknologi.

\section{Penonton Asian Games}

Berdasarkan data dari Kapanlagi Youniverse Socmed Team, jumlah keseluruhan penonton Asian Games yang menyaksikan melalui media di bawah Emtek Grup tercatat sebanyak 88.018.036 orang. Penonton yang menyaksikan melalui televisi SCTV sebanyak $12.83 \%$ atau 11.292 .772 orang, dan Indosiar sebesar $8.46 \%$ atau 7.446.729 plays. Persentase terbesar penonton menyaksikan siaran pertandingan Asian Games melalui kanal KLY yaitu sebanyak 23.032 .376 plays atau sekitar $26.17 \%$. Sisanya hampir 35\% menonton melalui kanal-kanal lain.

Sedangkan berdasarkan cara menontonnya, penonton secara live streaming terus meningkat dibanding penonton video on demand (VoD) sejak minggu pertama. 


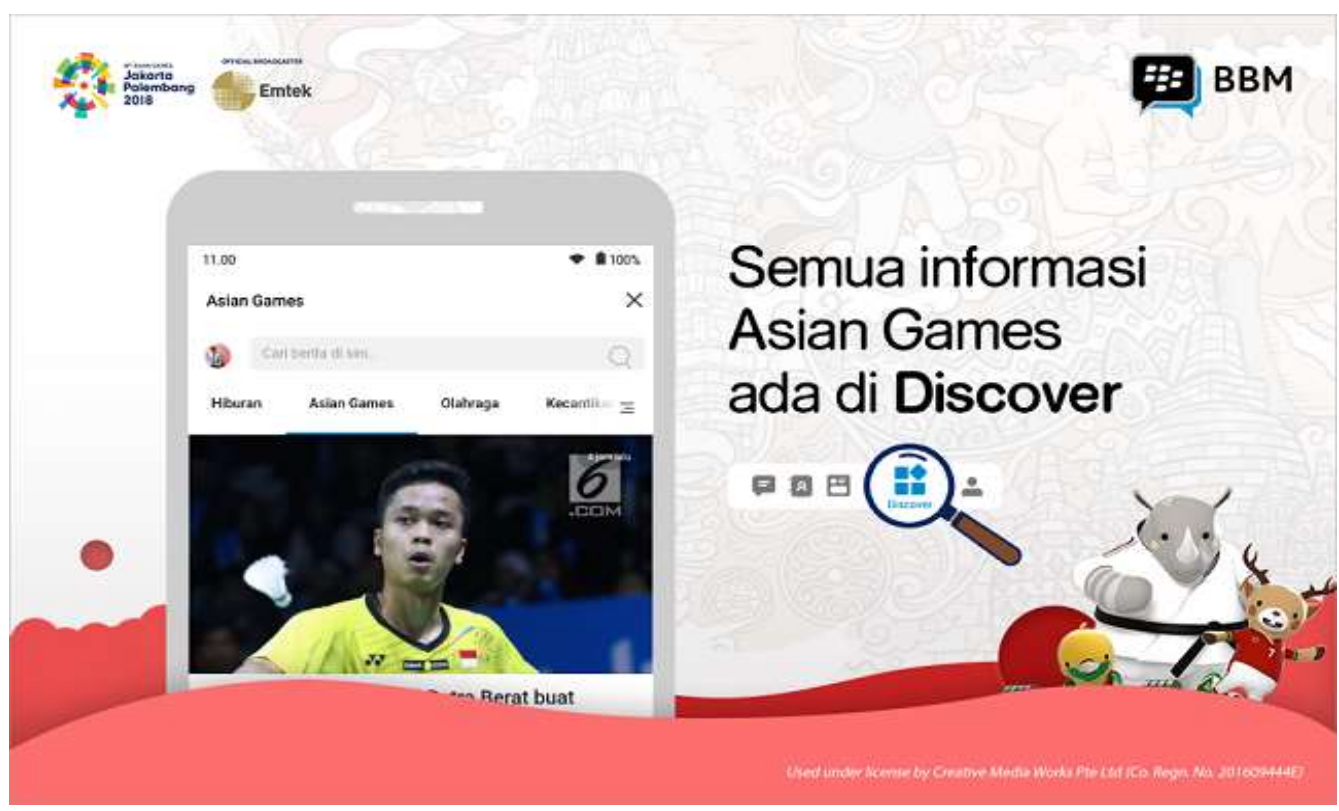

Sumber: Liputan6.com

Gambar 3. Tampilan Menu Discover BBM.

Data dari Kapanlagi Youniverse menunjukkan jumlah total penonton Asian Games 2018 secara live streaming dan VoD mencapai 100.100 .252 plays selama periode 10 Agustus s/d 2 September 2018 dengan komposisi 88\%:12\%. Pada tanggal 20 Agustus 2018 terjadi peningkatan secara drastis (spike) jumlah penonton yang mencapai 9.344.565 (Kapanlagi Youniverse Socmed Team, 2018). Hal ini terjadi ketika sedang berlangsung dua pertandingan yaitu bulutangkis beregu putera dan puteri, serta sepak bola putera Indonesia vs Hongkong. Acara lain yang memperoleh atensi besar adalah seremonial baik pembukaan maupun penutupan. Jumlah penonton acara pembukaan (opening ceremony) melalui live streaming sebanyak 1.308527 plays. Sedangkan acara penutupan (closing ceremony) mampu menarik penonton sebanyak 3.092.146 plays.

Data pada Gambar 4 menunjukkan adanya perubahan cara masyarakat dalam menonton tayangan Asian Games 2018. Menonton secara live streaming terus meningkat dibanding dengan cara VoD. Konvergensi media telah memberikan beragam pilihan dan masyarakat memiliki preferensi sendiri mengenai tayangan yang dapat mereka pilih melalui kanal-kanal digital yang disediakan.
Nielsen telah melakukan riset secara menyeluruh untuk melihat perilaku penonton ketika menyaksikan video melalui TV tradisional, internet, ponsel, dan perangkat lainnya. Hasil riset Nielsen tersebut menyebutkan adanya kebiasaan yang berubah ketika menonton televisi. Kini, banyak orang lebih menggunakan layanan streaming yang menggantikan kebiasaan menonton televisi atau mendengarkan radio melalui perangkat konvensional (Bizinsight, 2018). Pola konsumsi streaming video menjadi meningkat. Karaniya Dharmasaputra membenarkan hal tersebut. Saat ini yang menjadi pendorong pertumbuhan konsumsi video streaming dimotori oleh dua hal, pertama konten yang eksklusif seperti olahraga dan yang kedua tayangan drama (Karaniya Dharmasaputra, wawancara pada tanggal 8 April 2018).

Konvergensi juga memudahkan para penonton untuk berinteraksi. Pertandingan yang disiarkan melalui FTA bersifat linear atau hubungannya satu arah saja. Namun di Vidio.com dan kanal-kanal digital lain yang menyiarkan pertandingan secara daring memungkinkan terjadinya komunikasi di antara para penonton. 
Tabel 2

Penonton Asian Games

\begin{tabular}{lrr}
\hline Channel & Livestreaming & Plays \\
\hline KLY & 23.032 .736 & $26.17 \%$ \\
SCTV TV & 11.292 .772 & $12.83 \%$ \\
Indosiar Event & 8.608 .805 & $9.78 \%$ \\
Indosiar TV & 7.446 .729 & $8.46 \%$ \\
SCTV Event & 5.334 .459 & $6.06 \%$ \\
Channel 1 & 4.794 .043 & $5.45 \%$ \\
Channel 3 & 4.605 .546 & $5.23 \%$ \\
Channel 5 & 3.346 .397 \\
Channel 2 & 3.212 .238 & $3.80 \%$ \\
Channel 4 & 2.611 .205 & $3.65 \%$ \\
Channel 6 & 2.481 .159 & $2.97 \%$ \\
Channel 7 & 2.159 .636 & $2.82 \%$ \\
Channel 10 & 2.073 .860 & $2.45 \%$ \\
Channel 8 & 1.848 .395 & $2.36 \%$ \\
Channel 9 & 1.761 .787 & $2.10 \%$ \\
Channel 11 & 1.634 .843 & $2.00 \%$ \\
Channel 12 & 1.318 .989 & $1.86 \%$ \\
O Channel Event & 337.118 & $1.50 \%$ \\
O Channel TV & 118.079 & $0.38 \%$ \\
Total & 88.018 .036 & $0.13 \%$ \\
\hline
\end{tabular}

Sumber: Kapanlagi Youniverse Socmed
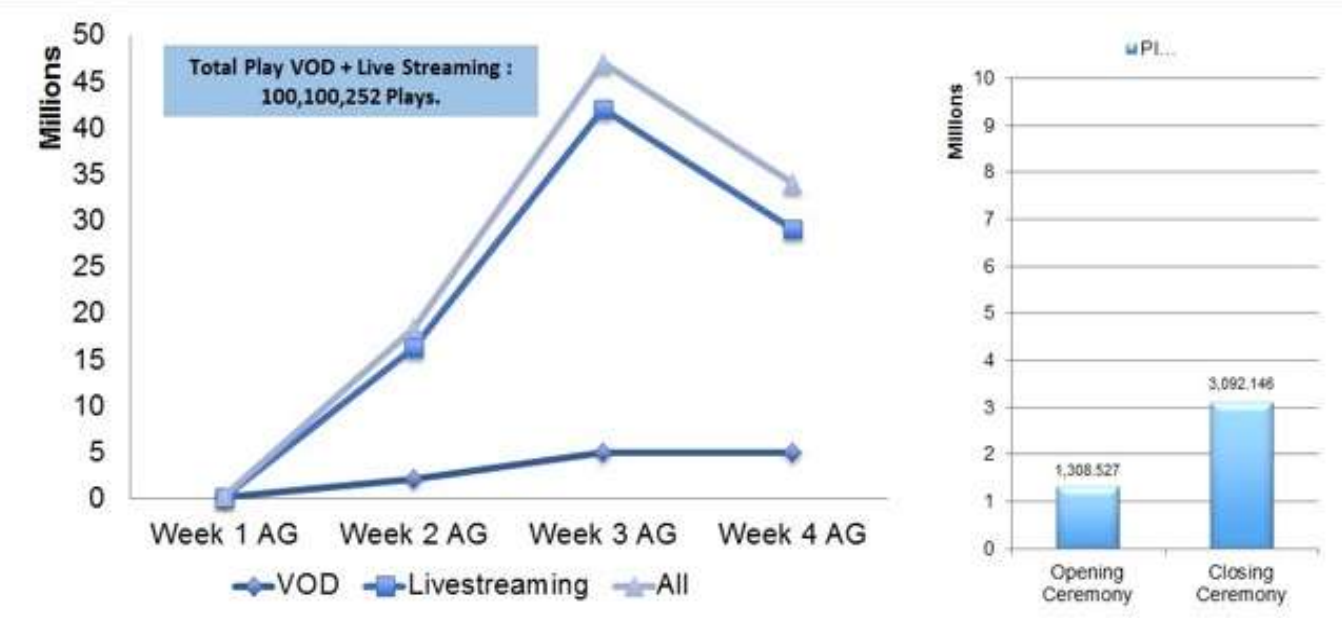

Sumber: Kapanlagi Youniverse

Gambar 4. Penonton Berdasarkan Konten. 
Sepanjang menyaksikan pertandingan melalui video streaming, penonton bisa berkomentar, memberikan tanda suka (like), saling berinteraksi dalam chat room yang tersedia. Tidak jarang suasana memanas akibat interaksi yang terjadi di media. Darojatun menceritakan salah satu contoh kejadian memanasnya chat room yang terjadi antara atlet Malaysia dan Singapura. OCA mengharuskan penggunaan geoblock supaya tidak melanggar kedaulatan orang yang punya hak siar di negara tetangga, sehingga ketika itu kebanyakan atlet-atlet cabang lain yang sudah selesai pertandingan dan belum pulang turut mendukung timnya dan menonton melalui Vidio.com. Mereka bisa ikut masuk chat room selama masih di wilayah Indonesia (Darojatun, wawancara pada 2 April 2019). Inilah yang membedakan dengan media linear. Penonton yang memilih kanal digital dapat ikut berpartisipasi dalam chat room.

\section{Media Sosial dan Interaksi Penonton}

Asian Games merupakan pertandingan olahraga yang melibatkan banyak negara, baik para atlet, media maupun khalayak penonton. Sepanjang perhelatan Asian Games, Indonesia sebagai tuan rumah menjadi terekspos, sehingga ini bukan saja menjadi ajang olahraga namun juga dapat berfungsi sebagai diplomasi publik. Maraknya penggunaan media sosial memudahkan siapa saja untuk mencari tahu lebih segala sesuatu mengenai Indonesia. Penggemar olah raga terutama dari negaranegara Asia dapat saling berinteraksi langsung di media sosial ketika pertandingan dilaksanakan. Media sosial bisa menjadi alat kekuatan lunak untuk memengaruhi pengguna lainnya dalam membuat dan berinteraksi dengan pesan (Widyanuratikah \& Putra, 2019). Terbukti bahwa tayangan Asian Games di samping memberi keuntungan secara finansial juga memberikan dampak kepada masyakat Indonesia, yaitu rasa persatuan yang kuat dalam mendukung atlet Indonesia.

Aktivitas penonton Asian Games 2018 di beragam media daring juga cukup tinggi. Hal ini menunjukkan indikasi terjadi perkembangan dalam menonton tayangan tersebut, khususnya terjadi perubahan cara berinteraksi penonton. Penonton tidak hanya menikmati tayangan tersebut tetapi ikut berinteraksi dengan penonton lain dengan cara memberi komentar, meramaikan hashtag dan mengunggah kembali tayangan melalui media sosial.

Kemudahan yang diberikan media daring tersebut juga memperluas interaksi antarpenonton dalam media sosial juga beragam. Mereka bersatu dalam mendukung perhelatan olahraga terbesar di Asia tersebut dengan meramaikan dalam hashtag "Indonesia bangga" di media sosial Instagram. Dalam hashtag tersebut jumlah mencapai jumlah 12.379 postingan, 106.938 komentar dan 7.531.699 yang memberikan like. Di akun Instagram Indosiar mencapai like dan komentar sebanyak 999.077, SCTV 597.406. Sedangkan di media sosial Twitter mencapai 50.572 cuitan dan 2.685.725.163 delivery timelines (Kapanlagi Youniverse Socmed Team, 2018).

Fenomena di atas membuktikan kebenaran pendapat Henry Jenkins mengenai era konvergensi. Kemajuan teknologi media di bidang media dapat mendorong audiens (penonton) untuk memberikan pengaruhnya pada arus media. Penonton juga memiliki kontrol terhadap isi media. Mereka juga mempelajari bagaimana cara agar dapat berinteraksi dengan audiens yang lain (Jenkins, 2006). Perkembangan media-media baru yang ditunjang teknologi tersebut telah memperluas jaringan sosial penonton Asian Games. Aktivitas menonton tayangan olahraga tidak lagi satu arah antara penonton dengan pesawat televisi. Mereka bisa saling berinteraksi secara langsung maupun tidak langsung melalui kanal-kanal digital yang didukung oleh media sosial. Penonton tetap dapat berinteraksi dengan yang lain meski tidak dapat menikmati tayangan secara langsung melalui YouTube, Instagram atau media sosial lainnya.

\section{PENUTUP}

\section{Simpulan}

Penelitian ini menjelaskan konvergensi yang dilakukan Emtek Grup untuk memudahkan masyarakat dalam menyaksikan pertandingan Asian Games 2018. Hasil penelitian menunjukkan bahwa meskipun 
metode free-to-air masih diminati, namun kanal-kanal digital yang disediakan oleh Emtek Grup lebih banyak menarik penonton. Selama Asian Games 2018, penonton antusias mendukung negaranya dengan menyaksikan siaran pertandingan cabang-cabang olahraga baik secara live streaming maupun $\mathrm{VoD}$. Hal ini sejalan dengan pernyataan bahwa konvergensi itu sendiri tidak membuat perubahan yang revolusioner pada konten tapi berkaitan erat pada ranah ekonomi yang membuat komunikasi dan distribusi konten menjadi lebih cepat, lebih fleksibel, dan lebih responsif pada permintaan konsumen.

Konvergensi yang dilakukan Emtek Grup tidak saja memudahkan akses ke tayangan, tapi juga telah memunculkan interaksi di antara para penonton. Hal ini menguatkan pandangan Jenkins bahwa konvergensi dapat memengaruhi kebudayaan manusia. Saat ini penonton Asian Games 2018 tidak hanya sekedar berinteraksi dengan televisinya, namun telah berkembang menonton sambil berinteraksi dengan penonton lainnya melalui berbagai saluran yang ada di media sosial.

Jaringan sosial dan penggunaan media daring mempermudah aspirasi penonton Asian Games 2018. Interaksi tersebut meningkatkan ikatan emosional antarpenonton dari berbagai kalangan. Ikatan emosional mereka diwujudkan dalam bentuk berbagai macam hashtag di media sosial. Setiap komentar ataupun status mengenai tayangan yang berkaitan dengan Asian Games dan mereka unggah ke media sosial selalui diakhiri dengan hashtag.

\section{Saran}

Dalam konvergensi media sebaiknya semua program sejak perencanaan awal (praproduksi) sampai produksi harus dipikirkan bagaimana program tersebut dapat di tayangkan baik untuk televisi free-to-air (FTA) maupun kanal digital. Ini bukan hanya sekedar memindahkan tayangan televisi ke digital atau sebaliknya. Semua konten disiapkan agar dapat digunakan untuk multiplatform. Dengan penayangan dalam multiplatform maka akan lebih banyak melibatkan penonton, sehingga interaksi akan semakin banyak dan program tersebut makin dikenal.

Penelitian mengenai konvergensi dan perubahan sosial ini masih potensial untuk terus digali dan dikembangkan. Interaksi penonton tidak lagi hanya satu arah, bahkan banyak memunculkan komunitas-komunitas baru. Komunikasi di antara penonton menarik untuk diteliti lebih lanjut, mengingat perbedaan sosial budaya mereka yang beragam. Kemajuan di berbagai bidang yang berkaitan dengan peningkatan konvergensi juga membuka peluang untuk mengembangkan penelitian lain.

\section{DAFTAR PUSTAKA}

Baran, S.J. (2010) Pengantar Komunikasi Massa: Literasi Media dan Budaya. 6th edition. Jakarta, Salemba Humanika.

Bizinsight (2018) Tren Video Online dan Pergeseran Perilaku Menonton di Masyarakat. [Online]. 2018. Available from: https://digiads.co.id/id/blog/editorial/trenvideo-online-pergeseran-perilaku-nontonmasyarakat/.

Briggs, A. \& Burke, P. (2000) Sejarah Sosial Media: Dari Gutenderg Sampai Internet. 1st edition. Jakarta, Yayasan Pustaka Obor Indonesia.

Budiawati, A.D. (2018) Keren, Pakai BBM Bisa Live Streaming Asian Games. [Online]. 2018. Available from: https://www.dream.co.id/techno/kerenkamu-bisa-live-streaming-asian-games-dibbm-180820r.html [Accessed: 13 November 2019].

Darojatun. (2018) Vice President of Sport Content Kapanlagi Youniverse (KLY). Wawancara, 2 April 2018.

Dharmasaputra, Karaniya. (2019) Deputy CEO Kapanlagi Youniverse. Wawancara, 8 April 2019.

Fauzan Jamaludin (2018) BBM tambah fitur baru Asian Games 2018. [Online]. 2018. Merdeka.com. Available from: https://www.merdeka.com/teknologi/bbmtambah-fitur-baru-asian-games-2018.html.

Goggin, G. (2006) Cell Phone Culture Mobile Technology in Everyday Life. London, Routledge.

Griffin, E. (2011) A First Look at Communication Theory. 5th edition. Boston, McGraw-Hill. 
Iskandar, Gilang. (2019) Corporate Secretary Surya Citra Media (SCM). Wawancara, 2 Mei 2019.

Jenkins, H. (2006) Convergence Culture: Where Old and New Media Collide. New York, NYU Press.

Julijanti, D.M. (2012) Dinamika Digitalisasi dan Konvergensi Media Televisi di Indonesia. Observasi. [Online] 10 (2), 93-102. Available from: https://jurnal.kominfo.go.id/index.php/obser vasi/article/view/67.

Kapanlagi Youniverse Socmed Team (2018) SOCIAL MEDIA REPORT ASIAN GAMES 2018.

Liputan6.com (2018) Emtek Group Siap Luaskan Gema Asian Games. [Online]. 2018. Liputan6.com. Available from: https://www.liputan6.com/bola/read/361726 9/emtek-group-siap-luaskan-gema-asiangames [Accessed: 20 November 2019].

Ma'arief Alyatalatthaf, M.D. (2018) Spasialisasi dan Praktik Monopoli Emtek Group. Jurnal ASPIKOM. [Online] 3 (5), 903. Available from: doi:10.24329/aspikom.v3i5.337.

McLuhan, M. (2003) Understanding Media The Extensions of Man. London \& NewYork, Gingko Press.

Nasrullah, R. (2014) Teori dan Riset Media Siber (Cybermedia). 1st edition. Jakarta, Kencana Prenada Media Group.

Nielsen (2013) Action Figures: How Second Screens are Transforming TV Viewing. [Online]. 2013. Nielsen.com. Available from: https://www.nielsen.com/us/en/insights/artic le/2013/action-figures-how-second-screensare-transforming-tv-viewing/ [Accessed: 27 November 2019].

Nielsen (2018) Penghujung Asian Games 2018 Masih Memikat Nasionalisme Pemirsa Televisi dan Pengiklan. [Online]. 2018. Nielsen.com. Available from: https://www.nielsen.com/id/en/insights/articl e/2018/penghujung-asian-games-2018- masih-memikat-nasionalisme-pemirsatelevisi-dan-pengiklan/ [Accessed: November 2019].

Nistanto, R.K. (2016) Grup Media Emtek Jalin Kerja Sama Rp 2,7 Triliun dengan BlackBerry. [Online]. 2016. Available from: https://tekno.kompas.com/read/2016/06/28/0 7550017/grup.media.emtek.jalin.kerja.sama. rp.2.7.triliun.dengan.blackberry [Accessed: 9 November 2019].

Preston, P. (2001) Reshaping Communications. London, Sage Publication.

Setyobudi, C. \& Sjailendra, S. (2017) Peluang Pay TV Menggeser Dominasi Free To Air TV di Perkotaan. WACANA, Jurnal Ilmiah Ilmu Komunikasi. [Online] 16 (1), 126. Available from: doi:10.32509/wacana.v16i1.8.

Shirky, C. (2010) Cognitive Surplus: How Technology Makes Consumers into Collaborators. Gingko Press.

Sudibyo, Agus. (2019) Direktur Indonesia New Media Watch. Wawancara, 20 Mei 2019.

Tempo.co (2018) 3 Fitur Baru BBM Ini Bantu Pengguna Nikmati Asian Games 2018. [Online]. 2018. Tempo.co. Available from: https://tekno.tempo.co/read/1119132/3-fiturbaru-bbm-ini-bantu-pengguna-nikmatiasian-games-2018 [Accessed: 20 November 2019].

Widyanuratikah, I. \& Putra, Y.M.P. (2019) Media Sosial Bisa Menjadi Alat Diplomasi Kebahasaan. [Online]. 2019. Available from: https://republika.co.id/berita/pendidikan/edu action/19/07/10/puf26x284-media-sosialbisa-menjadi-alat-diplomasi-kebahasaan.

Yuliawati (2018) Anak Usaha Emtek Grup Resmi Umumkan Akuisisi Situs Kapan Lagi. [Online]. 2018. Katadata.co.id. Available from:

katadata.co.id/yuliawati/digital/5e9a5603c56 b1/anak-usaha-emtek-grup-resmi-umumkanakuisisi-situs-kapan-lagi [Accessed: 9 November 2019]. 